\title{
Stem Cells in Endometrium and Regeneration
}

Bahar L*

Department of Stem cell and Regenerative Medicine, Mersin University, Turkey

DOI: $\underline{10.36348 / \text { sjbr.2019.v04i12.007 }}$

| Received: 19.12.2019 | Accepted: 26.12.2019 | Published: 30.12.2019

*Corresponding author: Bahar L

\section{Abstract}

Objective: The endometrium plays a key role in the fertility and endometrial pathology and gains great importance in the female reproductive system. It is important in terms of fertility and endometrial pathology with its mechanism and regulatory factors. Aim: This study highlights the complex process of endometrial regeneration and the researchs aimed at explaining the ability of endometrial stem cells to new remedy to the treatment of infertility as well as some diseases. Conclusion: There is no doubt that the endometrium has unlimited ability to regenerate any tissue. Today, they are in the various stages of experimentation in cell-based therapies of the regenerative medicine and will open hopeful avenues in treating heavy or fatal diseases by using stem cells. Beside endometrial diseases and infertility, an extensive range of clinical practices have included tests of stem cells in the endometrium. Furthermore, this study summarizes the identification of stem cells and regeneration properties in the endometrium.

Keywords: Endometrium, Infertility, Stem cell, Regeneration.

Copyright @ 2019: This is an open-access article distributed under the terms of the Creative Commons Attribution license which permits unrestricted use, distribution, and reproduction in any medium for non-commercial use (NonCommercial, or CC-BY-NC) provided the original author and source are credited.

\section{INTRODUCTION}

One of the valid solutions is to treat numerous degenerative diseases in stem cell therapy, and clinical experimentations are currently trying to determine their administrations to humans. Due to ethical subjects and the risk of tumors, the practical exploiture of stem cells has only recently begun [1].

The uterus is a certain organ characterized by morphological adaptation with reproductive function. Both the myometrium and endometrium are able to modify their histological structure to assistance fetal development. The stunning changes of endometrium is important in implantation and nutrition of the embryo that is protected by myometrium. The ovarian steroid hormones cause the periodic evolution of endometrium, under the modulation of neuroendocrine hypothalamichypophyseal system [2].

The regeneration of the human endometrial mucosa, a dynamic tissue, is subjected to periodical functional morphologic changes under the influence of sex hormones that change during each menstrual cycle in women's reproductive life. The post-menopausal endometrium responds exogenously estrogen-like [3]. Schwab et al. expressed that clonogenic stromal and epithelial cells are present in the inactive endometrium. This inactive endometrium lacks functionalis and is mostly basalis, therefore the clonogenicity of the inactive endometrium reinforcements the existence of an endometrial stem cell niche in the basalis [4]. Furthermore, it has demonstrated that clonogenic epithelial and stromal cells can be found in the inactive endometrium. These datum support future studies aimed at identifying assumed human endometrial epithelial and stromal stem/progenitor cells and demonstrating the notion that these cells are independent of the hormone. In addition, a small population of MSC-like cells in the endometrium that may be responsible for cyclic growth and may provide an MSC resource for tissue engineering applications [5]. The endometrium is composed of luminal and glandular epithelial cells and an important vascularized stroma; so many studies have been conducted to identify epithelial and mesenchymal stem / progenitor cells [6].

The differentiation potential of assorted multipotent mesenchymal stem/stromal cells (MSCs) populations and of cultured endometrial stromal fibroblasts has been verified [7]. İt has been expressed that the cultured human endometrial stromal fibroblasts also differentiated into a hematopoietic lineage generating CD41a and CD42b polyploid megakaryocytes that released platelets in vitro, state the plasticity of cultured endometrial stromal fibroblasts [8]. Particular markers of endometrial MSC have been 
identified. Co-expression of CD146 and PDGF-R $\beta$ isolates clonogenic stromal cells (CFU), sublimating for endometrial MSC 8-10 fold over unfractionated stromal cells [5]. It is clear that endometrial stromal fibroblasts are a large mesodermal multipotential. The gene expression profile of cultural epithelial and stromal SP cells produced a common gene signature and a gene signature that showed a significant overlap of differentially organized genes, perhaps presenting a single stem / progenitor cell phenotype [9]. However, this alike gene signature may have been reasoned by the lack of purity of the stromal SP and epithelial cultures [10]. Cultured stromal fibroblasts from primary trimester and decidua displayed featured properties of MSC clonogenicity (2-18\%), mesodermal lineage distinction and surface marker phenotype [11,12]. In this case, there is no suspicion that further researches need to be attained in order to understand the relationship between Endometrial MSCs (eMSCs), decidual MSCs, endometrial stromal fibroblasts and decidual stromal fibroblasts [13].

\section{DISCUSSION}

Women's fertility depends on the quality of the endometrium. The insufficiently thick endometrium may lead to sub-fertility and IVF failure. Therefore, the use of stem cells in the treatment of endometrium provides endometrial renovation and increased fertility rates [14]. The positive results achieved in the therapy of Asherman syndrome are the best evidence. Endometrial MSCs initially tested in animal models [15] and later on in humans [16] have been used. Epithelial progenitor cells in endometrial unicellular suspensions obtained from hysterectomy tissue to allow testing of basal glands; is clonogenic cells [17]. Identification of epithelial progenitor markers will provide an opportunity to investigate its role, endometrial regeneration in normal cycling endometrium, and gynecological diseases associated with abnormal epithelial proliferation such as endometriosis, endometrial cancer and adenomyosis [3]. The monthly regeneration of the human endometrium, it is almost completely resected after the parturition and in postmenopausal women taking estrogen-based hormone replacement therapy [6]. After regeneration with estradiol valerate for 8 weeks; the thickness of the atrophic endometrium in postmenopausal women is similar to the thickness of the premenopausal endometrium. The identified Clonogenic eMSCs in the regenerated endometrium have alike self-renewal and multipotency to premenopausal eMSCs [18].

Some endometrial problems, including infertility due to insufficient thickness of the endometrium, can be effectively treated using MSC transplantation. Although similar in specific MSC characteristics derived from different organ sources, endometrial stem cells (EMSC) are subjected to temporal regulation during a menstrual cycle in a micro-peripheral niche found only in endometrial tissues. Because of the microenvironment niche, there is a need for progressive therapies using EMSC for endometrial disorders [19].

The silence of the newly isolated side population (SP) cells corresponds to the adult stem cells. The CFU in vitro and assays do not likely provide a microbial or stem cell niche in order to preserve adult stem cell characteristics, leading to experimental differences. The heterogeneity and weak clonogenicity making single cell culture impractical restrict the researchs of the endometrial SP. However, much proof suggests that endometrial stem/progenitor cells are enriched in the SP fraction [20,3]. Although many studies have been achieved on endometrial cells derived from bone marrow, most have not identified the type of bone marrow cells that contribute to the endometrium. The former protocols are typically designed to make the engraftment of hematopoietic stem cells (HSCs) possible. HSCs are widely known to cause nonhematopoietic lineages in other tissues [21], but this has been a subject of discord [22].

The studies following donor-specific markers after BM transplantation in patients and experimental animals have showed that the BM-derived participates to the endometrial tissue. Co-expression of donor and endometrial markers contributes to recognizing endometrial BM-derived cells in the absence of BMderived immune cell markers [23,24]. Bone marrow stem plasticity may also indicate the developmental origins of bone marrow cells because the mesoderm arises from mesothelium via epithelial transposition to mesichem [25]. These stem cells are naturally plastic, but further characterization on the biology of MSC subpopulations needs to be done in order to settle this controvertible issue [26]. Epithelial cells were not ordinarily sighted in cultured menstrual blood, because they were not present, were overlooked or had been coated by the stromal fibroblast populations [27] suggesting that epithelial progenitors are more likely located in the basalis and not normally shed in menstruation stage [26]. Cultured menstrual blood cells have been redifferentiated into the decidual cells [28]. Research on menstrual blood cells has mostly focused on the broad differentiation ability into endodermal, mesodermal, and ectodermal lineages and their potential use in cell-based therapies [29]. Increased Tcell proliferation by menSCs may be the basis for the maintenance of endometrial homeostasis to cope with increased infections, but may not be sufficient for the need for immunological tolerance to this semiallogeneic fetus [30].

Epithelial label retention cells (LRCs) were detected in mouse glands with altered menstrual irregularity and epithelial repair. During endometrial shedding, the lumen epithelium and then estrogenindependent epithelium rapidly repaired the loss of the 
BrdU tag, while the glandular epithelium remained silent [31,32]. It has been described that endometrial LRCs in mice play a functional role in endometrial regeneration in the estrogen replacement model using postnatal pulse labeling in ovariectomized mice [17].

It is not known whether there is a change in the number of clonogenic MSC-like cells excreted in the menstrual cycle for women in terms of endometriosis, and whether women exposed to endometriosis are more prone to endometrial stem / progenitor cells. It is also unclear whether endometrial stem / progenitor cells are shed retrograde in women with endometriosis [33].

There are many controversies regarding adult stem cell or differentiation plasticity, particularly bone marrow-derived stem cells. Probably transdifferentiation mediates nuclear reprogramming and altering the transcriptional activity of important developmental genes. One of the forms of metaplasia that leads to changes in the extracellular environment is this stage, and occurs in tissue damage conditions [34]. The changing cell phenotype may include mesenchymal epithelial transmission (MET) or epithelial mesenchymal transmission (EMT). It is known that this process occurs during embryogenesis and is epitomized again in carcinogenesis [35].

Alternative regenerative medicine approaches for the repair of bone, muscle, cartilage, tendon, fat and other connective tissues aim to use MSC's ability to diversify into different cell types after settling in tissuespecific scaffolds [36]. The structural aid and cell adhesion substrate can be provided by tissue scaffolds and gives the opportunity to present a large number of cells directly to the damaged site as a three-dimensional viable tissue patch [37]. Transplanted MMCs reduce the area of myocardial infarction (MI) in the rat model, with cardiomyocytes derived from MMC observed in the area of myocardial infarction in vivo, they also significantly improved heart function. Furthermore, a decrease in left ventricular fibrosis was also achieved in heart transplanted hearts. Thus, MMCs can be a potential new, easily accessible material source for cardiac stem cell-based therapy [38]. Stromal fibroblasts obtained from many tissues have many similar properties, such as immunomodulatory properties, advanced differentiation, and surface marker phenotype, with MSC, and their gene expression profiles are unique and reflect the tissues from which they originated [39]. The human endometrium also contained a scarce population with MSC and fibroblast properties that could be partially purified in the CD146 PDGF-Rb population, indicating a hierarchy of the MSC-fibroblast lineage. The overlapping functions of stromal fibroblasts and eMSC abstain from the need to collect a rare population of CFU or CD146 PDGF-Rb for potential use in regenerative medicine [26].
The endometrium is characterized by its sensitivity to sex steroid hormone, cellular complexity, and periodic regeneration, and is very important for answering stem / progenitor cell questions. Although some evidence suggests that bone marrow is the source of endometrial stem / progenitor cells, its relationship with stem / progenitor cells derived from cholelomic epithelium is not yet known. In addition, the relationship between embryonic processes between mesenchymal and epithelial transformations and the formation of adult stem / progenitor cells found in endometrial disorders such as endometriosis and perhaps endometriosis has not yet been established. Studies to address these problems allow molecular genetics and epigenetic characterization, the development of new animal models, and perhaps future investigations that lead to the emergence of more specific markers for the identification of endometrial stem / progenitor cells. This situation will allow the investigation of the potential role of stem / progenitor cells of the endometrium in gynecological diseases [13, 26]. Furthermore, the effect of these cells on gynecological disorders involving abnormal endometrial reproduction, such as endometrial cancer, endometriosis and adenomyosis, can be investigated by identifying $\mathrm{N}$-cadherin as the main marker of endometrial epithelium [40].

\section{CONCLUSION}

Many new hypotheses regarding endometrial renewal and implantation have resulted from advances in endometrial stem cell research over the past decade. The easy attainment to the stem cells in the endometrium and their high ability to reproduce make them ideal postulates for cellular therapy. It is important to recognize the latest signals of endometrial stem cells so as to simplify their isolation and futurity practices.

Beside endometrial diseases and infertility, a broad range of clinical practices have included tests of stem cells in the endometrium. More clinical trials are necessary to get over the administration limits and improve the use of stem cells in the endometrium.Endometrial stem/progenitor cells are present in the endometrium and presumably play a staminal role in tissue stability during the normative endometrial function. Researches have not resoluted the role of BM derived endometrial cells in endometrial physiology and function yet. The communication between endometrial stem cells and the other cells in some cases opens the perspective of specific treatment as therapeutic means in the future.

\section{REFERENCES}

1. Crisan, M., Yap, S., Casteilla, L., Chen, C. W., Corselli, M., Park, T. S., ... \& Norotte, C. (2008). A perivascular origin for mesenchymal stem cells in multiple human organs. Cell stem cell, 3(3), 301313. 
2. Bockeria, L., Bogin, V., Bockeria, O., Le, T., Alekyan, B., Woods, E. J., ... \& Patel, A. N. (2013). Endometrial regenerative cells for treatment of heart failure: a new stem cell enters the clinic. Journal of translational medicine, 11(1), 56.

3. Gurung, S., Deane, J. A., Masuda, H., Maruyama, T., \& Gargett, C. E. (2015, September). Stem cells in endometrial physiology. In Seminars in reproductive medicine (Vol. 33, No. 05, pp. 326332). Thieme Medical Publishers.

4. Schwab, K. E., Chan, R. W. S., \& Gargett, C. E. (2005). Putative stem cell activity of human endometrial epithelial and stromal cells during the menstrual cycle. Fertility and sterility, 84, 11241130 .

5. Schwab, K. E., \& Gargett, C. E. (2007). Coexpression of two perivascular cell markers isolates mesenchymal stem-like cells from human endometrium. Human reproduction, 22(11), 29032911.

6. Gargett, C. E., \& Ye, L. (2012). Endometrial reconstruction from stem cells. Fertility and sterility, 98(1), 11-20.

7. Dominici, M. L. B. K., Le Blanc, K., Mueller, I., Slaper-Cortenbach, I., Marini, F. C., Krause, D. S., ... \& Horwitz, E. M. (2006). Minimal criteria for defining multipotent mesenchymal stromal cells. The International Society for Cellular Therapy position statement. Cytotherapy, 8(4), 315-317.

8. Wang, J., Chen, S., Zhang, C., Stegeman, S., PfaffAmesse, T., Zhang, Y., ... \& Chen, Y. (2012). Human endometrial stromal stem cells differentiate into megakaryocytes with the ability to produce functional platelets. PLoS One, 7(8), e44300.

9. Cervelló, I., Gil-Sanchis, C., Mas, A., DelgadoRosas, F., Martínez-Conejero, J. A., Galán, A., ... \& Horcajadas, J. A. (2010). Human endometrial side population cells exhibit genotypic, phenotypic and functional features of somatic stem cells. PLoS One, 5(6), e10964.

10. Wang, H., Jin, P., Sabatino, M., Ren, J., Civini, S., Bogin, V., ... \& Stroncek, D. F. (2012). Comparison of endometrial regenerative cells and bone marrow stromal cells. Journal of translational medicine, 10(1), 207.

11. Dimitrov, R., Kyurkchiev, D., Timeva, T., Yunakova, M., Stamenova, M., Shterev, A., \& Kyurkchiev, S. (2010). First-trimester human decidua contains a population of mesenchymal stem cells. Fertility and sterility, 93(1), 210-219.

12. Castrechini, N. M., Murthi, P., Qin, S., Kusuma, G. D., Wilton, L., Abumaree, M., ... \& Kalionis, B. (2012). Decidua parietalis-derived mesenchymal stromal cells reside in a vascular niche within the choriodecidua. Reproductive sciences, 19(12), 1302-1314.

13. Gargett CE, Schwab KE, Deane JA. (2016 ) Endometrial stem/progenitor cells: the first 10 years. Human Reproduction Update Vol.22: 2 pp. 137-163.

14. Cervelló I, Mas A, Gil-Sanchis C, Simón C. (2013) Somatic stem cells in the human endometrium. Semin Reprod Med 31(1): 69-76.

15. Masuda, H., Maruyama, T., Hiratsu, E., Yamane, J., Iwanami, A., Nagashima, T., ... \& Tamaoki, N. (2007). Noninvasive and real-time assessment of reconstructed functional human endometrium in $\mathrm{NOD} / \mathrm{SCID} / \gamma$ cnull immunodeficient mice. Proceedings of the National Academy of Sciences, 104(6), 1925-1930.

16. Nagori, C. B., Panchal, S. Y., \& Patel, H. (2011). Endometrial regeneration using autologous adult stem cells followed by conception by in vitro fertilization in a patient of severe Asherman's syndrome. Journal of human reproductive sciences, 4(1), 43.

17. Chan, R. W., Kaitu'u-Lino, T. U., \& Gargett, C. E. (2012). Role of label-retaining cells in estrogeninduced endometrial regeneration. Reproductive sciences, 19(1), 102-114.

18. Ulrich, D., Tan, K. S., Deane, J., Schwab, K., Cheong, A., Rosamilia, A., \& Gargett, C. E. (2014). Mesenchymal stem/stromal cells in postmenopausal endometrium. Human reproduction, 29(9), 1895-1905.

19. Phermthai, T., Tungprasertpol, K., Julavijitphong, S., Pokathikorn, P., Thongbopit, S., \& Wichitwiengrat, S. (2016). Successful derivation of xeno-free mesenchymal stem cell lines from endometrium of infertile women. Reproductive biology, 16(4), 261-268.

20. Arai, F., Hirao, A., Ohmura, M., Sato, H., Matsuoka, S., Takubo, K., ... \& Suda, T. (2004). Tie2/angiopoietin-1 signaling regulates hematopoietic stem cell quiescence in the bone marrow niche. Cell, 118(2), 149-161.

21. Krause, D. S., Theise, N. D., Collector, M. I., Henegariu, O., Hwang, S., Gardner, R., ... \& Sharkis, S. J. (2001). Multi-organ, multi-lineage engraftment by a single bone marrow-derived stem cell. Cell, 105(3), 369-377.

22. Wagers, A. J., \& Weissman, I. L. (2004). Plasticity of adult stem cells. Cell, 116(5), 639-648.

23. Taylor, H. S. (2004). Endometrial cells derived from donor stem cells in bone marrow transplant recipients. Jama, 292(1), 81-85.

24. Alawadhi, F., Du, H., Cakmak, H., \& Taylor, H. S. (2014). Bone marrow-derived stem cell (BMDSC) transplantation improves fertility in a murine model of Asherman's syndrome. PLoS One, 9(5), e96662.

25. Phinney, D. G., \& Prockop, D. J. (2007). Concise review: mesenchymal stem/multipotent stromal cells: the state of transdifferentiation and modes of tissue repair-current views. Stem cells, 25(11), 2896-2902.

26. Gargett, C. E., \& Masuda, H. (2010). Adult stem cells in the endometrium. Molecular human reproduction, 16(11), 818-834. 
27. Musina, R. A., Belyavski, A. V., Tarusova, O. V., Solovyova, E. V., \& Sukhikh, G. T. (2008). Endometrial mesenchymal stem cells isolated from the menstrual blood. Bulletin of experimental biology and medicine, 145(4), 539-543.

28. Sugawara, K., Hamatani, T., Yamada, M., Ogawa, S., Kamijo, S., Kuji, N., ... \& Umezawa, A. (2014). Derivation of human decidua-like cells from amnion and menstrual blood. Scientific reports, 4 , 4599.

29. Ulrich, D., Muralitharan, R., \& Gargett, C. E. (2013). Toward the use of endometrial and menstrual blood mesenchymal stem cells for cellbased therapies. Expert opinion on biological therapy, 13(10), 1387-1400.

30. Aleahmad, M., Ghanavatinejad, A., Bozorgmehr, M., Shokri, M. R., Nikoo, S., Tavakoli, M., ... \& Zarnani, A. H. (2018). Menstrual blood-derived stromal stem cells augment CD4+ $\mathrm{T}$ cells proliferation. Avicenna journal of medical biotechnology, 10(3), 183.

31. Kaitu'u-Lino, T. U. J., Ye, L., \& Gargett, C. E. (2010). Reepithelialization of the uterine surface arises from endometrial glands: evidence from a functional mouse model of breakdown and repair. Endocrinology, 151(7), 3386-3395.

32. Kaitu'u-Lino, T. U. J., Ye, L., Salamonsen, L. A., Girling, J. E., \& Gargett, C. E. (2012). Identification of label-retaining perivascular cells in a mouse model of endometrial decidualization, breakdown, and repair. Biology of reproduction, 86(6), 184-1.
33. Bokor, A., Debrock, S., Drijkoningen, M., Goossens, W., Fülöp, V., \& D'Hooghe, T. (2009). Quantity and quality of retrograde menstruation: a case control study. Reproductive Biology and Endocrinology, 7(1), 123.

34. Tosh, D., \& Slack, J. M. (2002). How cells change their phenotype. Nature reviews Molecular cell biology, 3(3), 187.

35. Polyak, K., \& Weinberg, R. A. (2009). Transitions between epithelial and mesenchymal states: acquisition of malignant and stem cell traits. Nature Reviews Cancer, 9(4), 265.

36. Caplan, A. I. (2007). Adult mesenchymal stem cells for tissue engineering versus regenerative medicine. Journal of cellular physiology, 213(2), 341-347.

37. Atala, A. (2009). Engineering organs. Curr Opin Biotechnol. 20: 575-592.

38. Hida, N., Nishiyama, N., Miyoshi, S., Kira, S, Segawa, K., Uyama, T. (2008). Novel cardiac precursor-like cells from human menstrual bloodderived mesenchymal cells. Stem Cells, 26: 1695 1704.

39. Haniffa, M.A., Collin, M.P., Buckley, C.D., Dazzi, F. (2009). Mesenchymal stem cells: the fibroblasts new clothes? Hematologica, 94: 258-263.

40. Nguyen, H.P.T, Li Xiao, James, A., Deane, T.K, Cousins, F.L. (2017). N-cadherin identifies human endometrial epithelial progenitor cells by in vitro stem cell assays. Human Reproduction, 32(11): 2254-2268. 